\title{
Lymph node retrieval in abdominoperineal surgical specimen is radiation time-dependent

\author{
Alain Sermier ${ }^{1}$, Pascal Gervaz*1, Jean F Egger ${ }^{2}$, My Dao ${ }^{1}$, Abdelkarim S Allal ${ }^{3}$, \\ Marta Bonet ${ }^{3}$ and Philippe Morel ${ }^{1}$
}

\begin{abstract}
Address: ${ }^{1}$ Department of Surgery, University Hospital Geneva, Switzerland, ${ }^{2}$ Department of Pathology, University Hospital Geneva, Switzerland and ${ }^{3}$ Department of Radiation Oncology, University Hospital Geneva, Switzerland

Email: Alain Sermier - alain.sermier@hcuge.ch; Pascal Gervaz* - pascal.gervaz@hcuge.ch; Jean F Egger - jeanfrancois.egger@hcuge.ch; My Dao - mydao@yahoo.com; Abdelkarim S Allal - abdelkarim.allal@hcuge.ch; Marta Bonet - marta.bonet@hcuge.ch;

Philippe Morel - philippe.morel@hcuge.ch

* Corresponding author
\end{abstract}

Published: 02 June 2006

World Journal of Surgical Oncology 2006, 4:29 doi:10.1186/1477-7819-4-29

This article is available from: http://www.wjso.com/content/4/1/29

(c) 2006 Sermier et al; licensee BioMed Central Ltd.

This is an Open Access article distributed under the terms of the Creative Commons Attribution License (http://creativecommons.org/licenses/by/2.0), which permits unrestricted use, distribution, and reproduction in any medium, provided the original work is properly cited.

\begin{abstract}
Background: A low yield of lymph nodes (LN) in abdominoperineal resection (APR) specimen has been associated with preoperative radiation therapy (XRT) in population-based studies, which may preclude adequate staging of anorectal carcinomas. We hypothesized that the number of LN retrieved in APR specimen was correlated with the dose and the timing of pelvic irradiation.
\end{abstract}

Patients and methods: We performed a retrospective study of 102 patients who underwent APR in a single institution between 1980 and 2004. Pathological reports were reviewed and the number of lymph nodes retrieved in APR specimens was correlated with: I) Preoperative radiation; 2) Dose of pelvic irradiation; and 3) Time interval between the end of XRT and surgery.

Results: There were 61 men and 41 women, with a median age of 66 (range 25-89) years. There were 12 patients operated for squamous cell carcinoma of the anal canal (SCCA) and 90 for rectal cancer. $83 \%$ and $46 \%$ of patients with anal and rectal cancer respectively underwent radical/ neoadjuvant radiotherapy. The mean $\pm S D$ number of $L N$ in APR specimen was $9.2 \pm 5$.9. The mean number of $L N$ in APR specimen was significantly lower in patients who underwent preoperative XRT $(8 \pm 5.5$ vs. $I 0.5 \pm 6 . I$, Mann-Whitney $U$ test, $P=0.02)$. The mean number of $L N$ was not significantly different after XRT in patients with SCCA than in patients with rectal cancer (6.2 \pm 5.3 vs. $7.8 \pm 5.3, p=0.33)$. Finally, there was an inverse correlation between the yield of $L N$ and the time elapsed between XRT and surgery (linear regression coefficient $r=-0.32, p=0.03$ ).

Conclusion: Our data indicate that: I) radiation therapy affects the yield of $L N$ retrieval in APR specimen; 2) this impact is time-dependent. These findings have important implications with regard to anatomic-pathological staging of anal and rectal cancers and subsequent decision-making regarding adjuvant chemotherapy.

\section{Introduction}

Adequate surgical lymphadenectomy and pathological evaluation of lymph nodes is a prerequisite for tumor staging and subsequent decision regarding adjuvant 
chemotherapy in patients with loco-regionally advanced rectal cancer [1]. In the 1997 TNM classification, of both the American Joint Committee on Cancer (AJCC) and the International Union Against Cancer (UICC), it is recommended that histological examination of a colorectal carcinoma (CRC) specimen should include a minimum of 12 lymph nodes [2]. This statement, however, was not intended to be a requirement for $\mathrm{pNO}$, but rather a guideline, and it appears that these criteria are met only in 31\% of the patients with rectal cancer [3]. This has important implications in clinical practice, since examination of nine or fewer lymph nodes is related to poor prognosis in patients with node-negative CRC [4-6].

Ionizing radiation has significant effects on the morphology of lymph nodes, including lymphocyte depletion and stroma fibrosis [7]. Indeed, data from population-based cancer registry indicate that preoperative XRT may have a negative impact on the number of lymph nodes retrieved from surgical specimen [8]. Other factors, which may affect lymph nodes yield in rectal cancer specimen, include tumor size, as well as examination by a dedicated histopathologist [9-11].

The aim of this study was to better define the impact of XRT in a population of patients who underwent abdominoperineal resection (APR) with or without previous XRT. We hypothesized; 1 ) that the yield of LN retrieval in APR specimen was lower in patients who had preoperative XRT; 2) that the effect of radiation on LN retrieval was dose-dependant; and 3) that the impact of preoperative XRT was time-dependent (i.e. the longer the delay between XRT and surgery, the more severe the lymph node depletion).

\section{Patients and methods}

This is a retrospective study of consecutive series of patients, who had underwent abdominoperineal resection for a histologically proven adenocarcinoma of the rectum or squamous cell carcinoma of the anal canal at University Hospital Geneva between September 1980 and February 2004. The total number of lymph nodes identified within the APR specimen was derived from the histology report in each case. Using these reports together with the patient notes the following information was recorded for each patient: age, gender, site of tumor (anal canal or lower rectum), TNM stage, preoperative radiotherapy status (short-course, long-course or none), dose of radiation delivered to the tumor, and finally the time elapsed between the end of XRT and surgical resection.

\section{Radiation techniques}

Patients with anal cancer were irradiated according to a previously described protocol [12]. Shortly, external beam radiation therapy (EBRT) was delivered in two sequences, with generally a median gap of 6 weeks or less between the sequences. For the first sequence external beam radiation therapy (EBRT) was used to a median dose of 39.6 Gy using mega-voltage photon beams. Boost treatment consisted of an additional dose of $20 \mathrm{~Gy}$ to the initial involved areas either using EBRT or brachytherapy. Patients with rectal cancer were treated preoperatively to a total dose of 45-50 Gy or a biologically equivalent dose using different RT fractionations as previously described [13]. The initial target volume included the tumor and any enlarged lymph nodes, perirectal and internal iliac lymph nodes, as well as the presacral area. Generally one posterior and two lateral Mega-voltage photon beams were used.

\section{Surgical technique}

The standardized procedure for APR included full mobilization of the rectum with sharp dissection in the plane anterior to Waldeyer's fascia down to the level of the levator muscles, in accordance with the Total Mesorectum Excision (TME) technique. Proximal section of the sigmoid colon was performed after ligature of the superior rectal artery or the inferior mesenteric artery. The perineal dissection encompassed the perianal skin, anal sphincters before dividing laterally the levators and the anal coccygeal ligament posteriorly.

\section{Histological technique}

Dissection of the specimen was performed according to a standard operating procedure, which did not change significantly over the course of the study. Lymph nodes were identified by direct inspection and manual palpation after close transverse slicing of the mesorectum and sigmoid mesentery. Histological technique involved careful standard dissection and direct inspection. Neither fat clearance, nor sentinel node mapping methods were used in this series of patients.

\section{Statistical analysis}

Statistical analyses were undertaken by means of the software package Statgraph 3.0 software for Windows (Statgraph Software Inc., San Diego, CA). Quantitative data were expressed as mean $\pm S D$, or median (range). Groups' comparisons were made using Fisher's exact test for categorical variables, and Student t-test, Mann-Whitney U test or analysis of variance (ANOVA) for continuous variables. P-values less than or equal to a two-sided alpha-level of 0.05 were considered statistically significant.

\section{Results}

There were 61 men and 41 women, with a median age of 66 (range 25-89) years. 12 patients underwent APR for SCCA and 90 for rectal cancer. Ten (83\%) SCCA patients and $42(46 \%)$ rectal cancer patients underwent preoperative radiotherapy. The clinico-pathological characteristics 
of patients and tumors according to preoperative XRT status are summarized in Table 1. Six patients had no evidence of residual tumor within the surgical specimen (Stage 0). There were 30 Stage I, 20 stage II, and 46 stage III patients. Of these, $44 \%$ of patients had positive lymph nodes (N1-2) in the specimen. The mean delay between the end of XRT and surgery was 151 (range 57-231) days in SCCA patients, and 49 (4-229) days in patients with rectal cancer (Mann-Whitney $U$ test, $\mathrm{p}=0.001$ ).

\section{Yield of LN retrieval in APR specimen according to XRT status}

When considering all patients together, the mean number of LN in surgical specimen was $9.2 \pm 5.9$ (median 8 , range $0-24)$. The mean number of LN in APR specimen was significantly lower in patients who underwent preoperative XRT ( $8 \pm 5.5$ vs. $10.5 \pm 6.1$, Mann-Whitney $U$ test $\mathrm{p}=0.02)$ (Figure 1).

\section{The effects of preoperative XRT according to the dose of irradiation}

We compared the number of LN in APR specimen of 10 SCCA patients (who received a mean dose to the pelvis of $60 \mathrm{~Gy}$ ) with 42 rectal cancer patients who were treated with a mean dose of $45 \mathrm{~Gy}$. The mean number of LN was lower after XRT in patients with SCCA than in patients with rectal cancer; however, this difference did not reach statistical significance $(6.2 \pm 5.3$ vs. $7.8 \pm 5.3, \mathrm{p}=0.33)$ (Figure 2).

\section{The effects of preoperative XRT are time-dependent}

Finally, we performed a regression analysis of the number of LN according to the delay between the end of XRT and the time of surgery. The median time elapsed was 50 days (range 4-231), and this delay was significantly longer in patients with SCCA than in patients with rectal cancer $(151 \pm 79$ vs. $49 \pm 35$ days, $\mathrm{p}<0.001)$. There was an inverse correlation between the yield of LN and the time elapsed between XRT and surgery (linear regression coefficient $\mathrm{r}=-0.32, \mathrm{p}=0.03$ ) (Figure 3 ).

\section{Discussion}

In this series the number of LN retrieved in APR specimen of rectal cancer patients with $(8 \mathrm{LN})$ or without $(10.5 \mathrm{LN})$ preoperative XRT are quite similar to large populationbased series from the US [3], and Europe [14], suggesting that the techniques of surgical lymphadenectomy and pathological examination used in our institution are adequate. Although this 25\% reduction in LN yield may seem of little clinical significance, it is noteworthy that $31 \%$ of patients in the irradiated group had 4 or less nodes in their surgical specimen, suggesting inadequate tumor staging in one third of patients who underwent preoperative radiation therapy. Thus, our first hypothesis proved to be correct; preoperative XRT significantly and negatively affects the yield of LN in APR specimen.

By contrast, we were unable to demonstrate that our second hypothesis was correct; although patients with SCCA were irradiated with higher doses, in comparison with rectal cancer patients, the difference in the number of LN according to the tumor type failed to achieve statistical significance. Actually, (and this demonstrates our third hypothesis to be right) our data emphasizes the impact of timing, more than the actual dose of radiation, on the number of lymph nodes retrieved from APR specimen. The impact of XRT on mesorectum lymph node retrieval is more pronounced when APR is delayed by several months after the end of pelvic irradiation [15]. The regression analysis in our study was greatly influenced by the 5 patients who underwent APR for recurrent anal cancer more than 5 months after the end of radiation therapy. Consequently, current protocols with longer intervals (68 weeks) between XRT and surgery for rectal cancer may result in increased tumor downstaging, but also in an

Table I: Clinicopathological characteristics of patients according to preoperative radiation therapy

\begin{tabular}{|c|c|c|c|}
\hline & CRT & NO CRT & $\mathbf{p}$ \\
\hline Age (median, range) & $61.5(25-82)$ & $67.5(28-89)$ & 0.33 \\
\hline Male gender (\%) & 61.5 & 58 & 0.84 \\
\hline Indication for APR & & & 0.001 \\
\hline Anal cancer & 10 & 2 & \\
\hline Rectal cancer & 42 & 48 & \\
\hline LN retrieved & $8.0 \pm 5.5$ & $10.5 \pm 6.1$ & 0.02 \\
\hline Cases with positive LN (\%) & 44.2 & 44 & 1.00 \\
\hline \multicolumn{4}{|l|}{ Pathological staging } \\
\hline 0 & 6 & - & \\
\hline 1 & 11 & 19 & \\
\hline II & 10 & 10 & \\
\hline III & 25 & 21 & \\
\hline
\end{tabular}

* Student $t$ test, Mann-Whitney $U$ test or Fisher's exact test, when indicated 


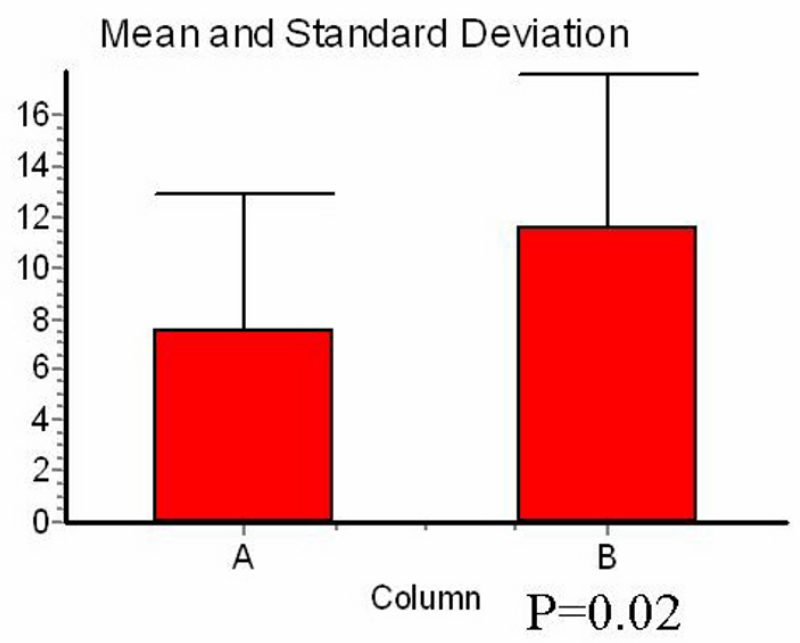

Figure I

Number of lymph nodes in APR specimen according to preoperative radiation therapy status.

inadequate yield of lymph nodes in the surgical specimen $[16,17]$.

The implications of our results are that, due to the widespread use of neoadjuvant XRT, the current TNM classification of anorectal cancers needs to be improved [18]. Pre-treatment staging using either magnetic resonance imaging or endorectal ultrasound (EUS) are accurate enough for the $\mathrm{T}$ stage, but have proven insufficient to determine lymph node involvement $[19,20]$. By comparison, and despite tumor down staging, pathological post-

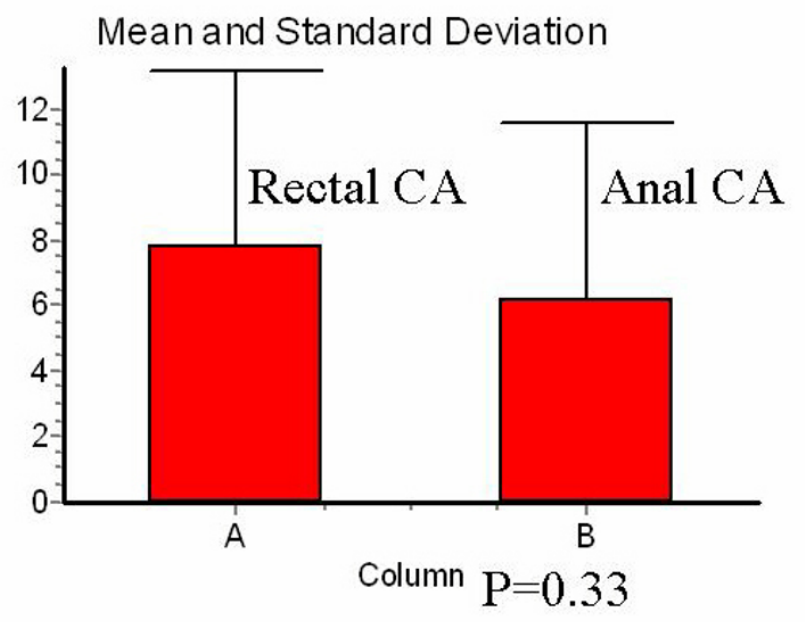

Figure 2

Number of lymph nodes in APR specimen according to tumor location.

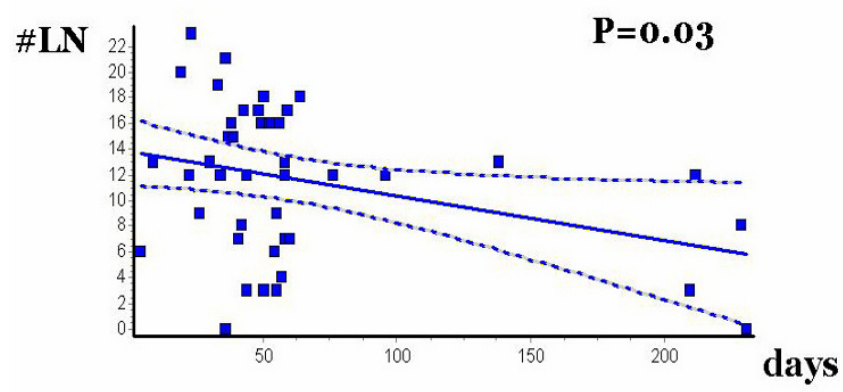

Figure 3

Linear regression analysis of lymph nodes in APR specimen according to interval between the end of pelvic irradiation and the time of surgery.

operative staging remained a very strong prognostic factor for both $\mathrm{T}$ and $\mathrm{N}$ stages $[21,22]$. Thus, the TNM staging system for rectal cancer, which currently does not take into account neoadjuvant XRT, remains pivotal for selection of patients who may benefit from additional chemotherapy, but the pathological $\mathrm{N}$ staging of irradiated specimen should be interpreted with caution.

\section{Summary}

The longer is the delay between XRT and surgery, the lower is the yield of LN in the mesorectum. Future efforts for improving the yield of mesorectal lymph node after pelvic irradiation should consider reinvestigating the role of extended but selective lymphadenectomy, perhaps using modern techniques of lymph node clearing [23]. Sentinel lymph node mapping is another promising option, which needs to be assessed in prospective studies $[24,25]$.

\section{Competing interests}

The author(s) declare that they have no competing interests.

\section{Authors' contributions}

AS conceived of the study; PG participated in its design and coordination and helped to draft the manuscript; JFE participated in the design of the study; MD performed the statistical analysis; ASA participated in the design of the study; MB participated in the design of the study; PM helped to draft the manuscript.

All authors read and approved the final manuscript.

\section{Acknowledgements}

Presented at the $46^{\text {th }}$ Annual Meeting of the Society for Surgery of the Alimentary Tract, Chicago (IL), May 14-18, 2005. 


\section{References}

I. Nelson H, Petrelli N, Carlin A, Couture J, Fleshman J, Guillem J, Miedema B, Ota D, Sargent D, National Cancer Institute Expert Panel: Guidelines 2000 for colon and rectal cancer surgery. National Cancer Institute Expert Panel. J Natl Cancer Inst 200 I 93:583-596.

2. Sobin LH, Greene FL: TNM classification: clarification of number of regional lymph nodes for pN0. Cancer 200I, 92:452.

3. Baxter NN, Virnig DJ, Rothenberger DA, Morris AM, Jessurun J, Virnig BA: Lymph node evaluation in colorectal cancer patients: a population-based study. I Natl Cancer Inst 2005 97:219-225.

4. Caplin S, Cerottini JP, Bosman FT, Constanda MT, Givel JC: For patients with Dukes' B (TNM Stage II) colorectal carcinoma, examination of six or fewer lymph nodes is related to poor prognosis. Cancer 1998, 83:666-672.

5. Swanson RS, Compton CC, Stewart AK, Bland KI: The prognosis of T3NO colon cancer is dependent on the number of lymph nodes examined. Ann Surg Oncol 2003, 10:65-7I.

6. Sarli L, Bader G, lusco D, Salvemini C, Mauro DD, Mazzeo A, Regina $G$, Roncoroni L: Number of lymph nodes examined and prog nosis of TNM stage II colorectal cancer. Eur J Cancer 2005 , 41:272-279.

7. Fajardo LF: Effects of ionizing radiation on lymph nodes. A review. Front Radiat Ther Oncol 1994, 28:37-45.

8. Baxter NN, Morris AM, Rothenberger DA, Tepper JE: Impact of preoperative radiation for rectal cancer on subsequent lymph node evaluation: a population-based analysis. Int J Radiat Oncol Biol Phys 2005, 6 I:426-43I.

9. Thorn CC, Woodcock NP, Scott N, Verbeke C, Scott SB, Ambrose NS: What factors affect lymph node yield in surgery for rectal cancer? Colorectal Dis 2004, 6:356-36I.

10. Miller EA, Woosley J, Martin CF, Sandler RS: Hospital-to-hospital variation in lymph node detection after colorectal resection. Cancer 2004, 101:1065-1071.

I I. Wright FC, Law CH, Last L, Khalifa M, Arnaout A, Naseer Z, Klar N, Gallinger S, Smith AJ: Lymph node retrieval and assessment in stage II colorectal cancer: a population-based study. Ann Surg Oncol 2003, 1 0:903-909.

12. Allal AS, Mermillod B, Roth AD, Marti MC, Kurtz JM: The impact of treatment factors on local control in T2-T3 anal carcinomas treated by radiotherapy with or without chemotherapy. Cancer 1997, 79:2329-2335.

13. Allal AS, Gervaz P, Gertsch P, Bernier I, Roth A, Morel P, Bieri S Assessment of quality of life in patients with rectal cancers treated by preoperative radiotherapy: a longitudinal prospective study. Int J Radiat Oncol Biol Phys 2005, 6 I: I I 29- I I 35.

14. Scheidbach H, Schneider C, Konradt J, Barlehner E, Kohler L, Wittekind $\mathrm{Ch}$, Kockerling $\mathrm{F}$ : Laparoscopic abdominoperineal resection and anterior resection with curative intent for carcinoma of the rectum. Surg Endosc 2002, 16:7-13.

15. Gervaz P, Allal AS, Villiger P, Buhler L, Morel P: Squamous cell car cinoma of the anus: another sexually transmitted disease. Swiss Med Wkly 2003, I33:353-359.

16. Francois Y, Nemoz C], Baulieux J, Vignal J, Grandjean JP, Partensky C, Souquet JC, Adeleine P, Gerard JP: Influence of the interval between preoperative radiation therapy and surgery on downstaging and on the rate of sphincter-sparing surgery for rectal cancer: the Lyon R90-0I randomized trial. J Clin Oncol 1999, 17:2396-2402.

17. Moore HG, Gittleman AE, Minsky BD, Wong D, Paty PB, Weiser M, Temple L, Saltz L, Shia J, Guillem JG: Rate of pathologic complete response with increased interval between preoperative combined modality therapy and rectal cancer resection. Dis Colon Rectum 2004, 47:279-286.

18. Burke HB: Outcome prediction and the future of the TNM staging system. J Natl Cancer Inst 2004, 96: |408-| 409.

19. Kim NK, Kim MJ, Yun SH, Sohn SK, Min JS: Comparative study of transrectal ultrasonography, pelvic computerized tomography, and magnetic resonance imaging in preoperative staging of rectal cancer. Dis Colon Rectum 1999, 42:770-775.

20. Chapet O, Romestaing P, Mornex F, Souquet JC, Favrel V, Ardiet JM, D'Hombres A, Gerard JP: Preoperative radiotherapy for rectal adenocarcinoma: Which are strong prognostic factors? Int J Radiat Oncol Biol Phys 2005, 6 I : I37 I-1377.
21. Stipa F, Zernecke A, Moore HG, Minsky BD, Wong WD, Weiser M, Paty PB, Shia J, Guillem JG: Residual mesorectal lymph node involvement following neoadjuvant combined-modality therapy: rationale for radical resection? Ann Surg Oncol 2004 I I:I87-I9I

22. Chan AK, Wong A, Jenken D, Heine J, Buie D, Johnson D: Posttreatment TNM staging is a prognostic indicator of survival and recurrence in tethered or fixed rectal carcinoma after preoperative chemotherapy and radiotherapy. Int J Radiat Oncol Biol Phys 2005, 6 I:665-677.

23. Volpe $C$, Rodriguez-Bigas M, Petrelli NJ: Wide perineal dissection and its effect on local recurrence following potentially curative abdominoperineal resection for rectal adenocarcinoma. Cancer Invest 1996, I 4: I-5.

24. Saha S, Monson KM, Bilchik A, Beutler T, Dan AG, Schochet E, Wiese $D$, Kaushal S, Ganatra B, Desai D: Comparative analysis of nodal upstaging between colon and rectal cancers by sentinel lymph node mapping: a prospective trial. Dis Colon Rectum 2004, 47: I767-I772.

25. Bilchik AJ, Nora DT, Sobin LH, Turner RR, Trocha S, Krasne D, Morton DL: Effect of lymphatic mapping on the new tumor-nodemetastasis classification for colorectal cancer. J Clin Oncol $2003,21: 668-672$.
Publish with Biomed Central and every scientist can read your work free of charge

"BioMed Central will be the most significant development for disseminating the results of biomedical research in our lifetime. "

Sir Paul Nurse, Cancer Research UK

Your research papers will be:

- available free of charge to the entire biomedical community

- peer reviewed and published immediately upon acceptance

- cited in PubMed and archived on PubMed Central

- yours - you keep the copyright

Submit your manuscript here:

http://www.biomedcentral.com/info/publishing_adv.asp
BiolMedcentral 